\section{The Effect of Learning Styles to Build Learner Autonomy}

\author{
Ratna Sajekti Rusli, Helena D., Soegiarto \\ Universitas Negeri Jakarta
}

\begin{abstract}
The purpose of this study was to investigate the effect of fielddependent and field-independent cognitive learning styles on learning achievement and the relation between cognitive learning and gender The subjects were SMU students of Social Science (IPS) and Mathematics and Natural Science (IPA) classes of SMUK Triyana. The scores of summative test of several school subject matters were used as the data. The results show that cognitive learning styles do not have any effect on the students' achievernent on History subject matter. However, cognitive learning styles influence English learning. This study also shows that gender does not affect achievement.
\end{abstract}

Keywords: cognitive learning style, field-dependent style, field-independent style, learning achievement.

Often times it is said that the United States is the only country that opens the door to society to interfere how school head masters should manage education and to participate in determining how teachers should teach in schools. This attitude that hardly appreciates the complexity of education is reflected in many reports on educational reform in the 1980s.

This attitude might be the remnants of a time when most of the people kew about teaching as much as the teachers did. Protagoras from Abdura who was often named the first professional teacher, in the 5th century B.C., though a superior orator, did not know about logic as well as generalization at all. Nevertheless he was the first professional teacher, a member of the Sophist group.

Socrates, a contemporary of Protagoras, introduced the system of logic and inquiry, as such he introduced to the world the teaching methodology of Socrates. By combining logic, inquiry, and charisma, Socrates helped the students to realize their ignorance, which was one of the prerequisites and one of the facilitators of effective learning.
In the 13th century Thomas from Aquinas succeeded in convincing the church to accept divergent thinking which opened wide opportunities for scientists to exercise their intellectual faculties to explore new fields in science. In the 16th century Sir Francis Bacon from England introduced to the world the scientific approach to investigate environments, thus he provided the foundation for the development of systematic teaching methodology in the future.

Advancement in the sense of thinking process and efficient teaching methodology was progressing very slowly indeed. It took approximately two thousand four hundred years for the teaching methodology to develop into a discipline of science. Only for the last 25 years has the science of teaching methodology shown some satisfactory result within short periods. Nevertheless as a discipline of science, teaching methodology cannot improve faster than our understanding about the learning process. Except teaching methodology other factors contribute to the success of the teaching-learning process, 0 . a. the factor of the learner himself, namely the types of cognitive learning styles and the learner autonomy. The existence of cognitive learning styles has been acknowledged and its relationship with as well as its effect on the surrounding variables have been investigated scientifically. How successful the role of the teacher is in promoting autonomy in his class, say English language class, may depend among others how far the teacher can recognize the cognitive learning styles of his students.

The fact that people differ from each other on a number of dimensions might not be taken into serious consideration. The difference in physical strength, age, gender, and maturity may easily be detected and be clearly recognized by every body. Even the difference in talent or basic competence can be known due to the observation by novelists, philosophers and poets long before the existence of scientific psychology. Some differences found in people may be due to unique learning history. Whatever the source of those difference may be, they have a sound impact on the methodology one designs the system of learning.

One of the differences among the students is their entry behavior. What is meant by entry behavior here is a set of skills and learning procedures the students take with them into their learning situation. Learning procedure here refers to prior learning experiences the students take with them into their new situation. For example, a student has to 
solve a long series of division problem, he has a capability in remembering a whole set of multiplication table which come in handy, this ability to remember the multiplication table is called learning procedure.

If we pay careful attention to a number of people studying any assignments, it is obvious the difference in each of their performances. Some people work faster than others; for some it takes longer time to study the material; some make fewer mistakes, etc. Such serious performances might be because of some factors such as, for example, heterogeneous learning procedure in the past or diversified maturity. Besides, differences in performance might be also due to inherent basic capacity and competence. Some students are smarter than others or they may have special talents such as in music or mathematics. Those special talents enable those students to be more apt to gain certain skills than other students.

Nevertheless, certain capacity will be lost through inactivity, it should be practiced again and again in order to develop. This capacity is learner autonomy, namely a capacity for detachment, critical reflection, decision making, and independent action (Little, 1991). Students should be encouraged to take responsibility for their own work, by being given some control over what, how and when they learn. Such students are more likely to be able to set realistic goals, plan programmes of work, develop strategies for coping with new and unforeseen situations, evaluate and assess their own work and, generally, to learn how to learn from their own successes and failures in ways which will help them to be more efficient learners in the future. All these will be much easier if the students (as well as the teachers) know their own cognitive learning styles and what effect they have on their academic achievement.

According to Weiner and Lerman (1996) cognitive learning styles is an inte-grated concept that by definition bridges over someone's personalcognitive dimension. The dimensions in Dembo's (1991) point of view, are reflective/impulsive and field-dependent/field-independent.

The difference in cognitive learning styles should be taken into serious consideration as one of the factors toward a successful students' learning autonomously. Besides, different cognitive style can cause different academic achievement.

Based on all the discussions above there arises several questions which can be turned into research questions or research problems; they are as follows:
1. Is there any different effect on the students' achievement between those whose cognitive learning style is field-dependent and those whose cognitive learning style are field-independent?

2. Which cognitive learning style has greater effect, that of fielddependent or that of field-independent?

3. Is there an interaction between cognitive learning styles and gender?

The main objective of this study is to get empirical data on the solution of the problems stated above, namely whether there is a significant effect on achievement between students who are field-dependent and field-independent by taking gender into consideration. The result of this study will become one of the important factors to a successful autonomous learning.

\section{THEORETICAL FRAMEWORK}

Cognitive learning styles can make a difference in student's academic performance. Once, an educational specialist said that in the $1960 \mathrm{~s}$ when there was a child that did not want to learn, the teachers and the school counselors tend to focus their attention on the child's intelligence, emotional condition, and spiritual conflict as the main reason for his unwillingness to learn. They were not looking for other factors that may cause (for example the cognitive learning style) the child not to want to learn. Two students having equal intelligence test scores could do their assignments with different cognitive style of learning. In his book Apllying Educational Psychology Dembo (1991) wants to show that a certain cognitive learning factor has more influence on achievement rather than intelligence.

This cognitive learning styles has an important implication for the student-teacher interaction as well as for determining the methodology going to be implemented. If teachers are willing to spend more time studying thoroughly about this cognitive learning styles, there will be more opportunities to develop specific material and teaching procedure for certain students. Designing a teaching-learning procedure based on cognitive learning styles is a good example of adjusting to students' differences in order to produce a more effective result.

One dimension of cognitive learning styles that has been studied most often is the field-dependent and field-independent. This dimension serves as a standard how far students can cope with the influence of some 
elements, such as background/environment (the field) that may deviate if they try to distinguish aspects which are relevant to certain situation. The more detached a student is from things that can detract him, the more analytic he is and the more he is independent from the field or his environment. The more dependent one is or the more he cannot detach himself from things that trouble him, the more helpless he seems and the more he is dependent on his field surroundings (Dembo, 1991).

In his article Stipek and Weisz (1994) show some characteristics of people who are field-dependent and those who are field-independent. People who are field-dependent pay very much attention to the society that surrounds them and they are dependent on other people in adopting their attitude and belief. It can be seen from them that they are very sensitive towards the surrounding society. On the other hand those who are field-independent show greater interest in abstract aspects and all kinds of stimulus objectives. These two types of people react differently towards their surroundings and environments.

Ware and Lee (1996) also discuss the consequences of the different orientation between the two types of people that have different cognitive learning styles in reference to the teaching-learning material preferred by each type respectively. Furthermore they said there was no significant data showing that there was a difference in achievement between those who have field-dependent cognitive learning style and those who have field-independent cognitive learning style in general knowledge and rote learning. Although it seemed that they reacted towards a different stimulus: people who have field-dependent cognitive leaming style are better in learning and remembering objective material (Dembo, 1991).

Another difference between those two types of cognitive learning styles is the fact that social reinforcement has a greater impact on people who are field-dependent rather than on those who are field-independent. Usually the teachers say that students react differently towards praise and reproach. Whether a student needs social reinforcement or not may depend on his cognitive learning style, either field-dependent or fieldindependent.

Students with those two cognitive learning styles react in various ways towards the teaching-learning material from the aspect of its organization. If the material is not neatly organized yet, the students should arranged it. Field-independent students are more competent in mastering the organization needed to arrange the teaching-learning mate- rial. If the material has already been neatly organized, then the learning competency for both learning styles (field-dependent and field-independent) students are equal.

An important aspect in reference to the dimension of this cognitive learning style is that it is very much influenced by culture. In line what Stipek (1994) stated field-dependent comes from the experience of respecting other people's customs and habits in the society, from the feeling of being protected and the existence of a close relationship between mother and child. Ramirez and Price-Williams (1991) showed that Mexican-American children are more field-dependent, while the Euro-American children are more field-independent.

According to Cohen the greater part of the school environment reflects field-independent style Consequently Mexican-American children and other children who are used to the field-dependent environment will find much difficulty in adapting themselves to the school environment. Ramirez and Castaneda are of the opinion that the teachers should help those children in developing into two-fold cognitive style, namely fielddependent style as well as field-independent style (Dembo, 1991).

Witkin and friends developed a set of test which they called fielddependence. Students who are field-dependent depend very much on their surroundings (usually what is real). Witkin's set of test is to measure the dimension of field-dependent. From Witkin's test if it is obvious that someone has a field-independent cognitive learning style, then he has a tendency to be more independent in society (Hagen and Thorndike, 1994).

The difference in gender within the cognitive scope seems to be very small, as was revealed by many results of researches. Although in matters of general intelligence and general knowledge there is no difference between male and female students, the girls are much better in doing verbal assignments and the boys are more excellent in mathematics and visual-spatial assignments. In reference to standard achievement tests the girls have got higher scores than the boys in subject matters that have some relation with verbal competence, swiftness of perception, and accuracy; while the boys are much better than the girls in subject matters that use reasoning abilities and spatial skills. In the elementary schools the girls are much better in achievement that the boys, but when they are in high schools the boys are better that the girls. More boys than girls do not like to read, those boys form a $75 \%-85 \%$ of the children who cannot read in the senior high schools (Dembo, 1991). 
Concerning the personality of the children, the girls are in general more dependent and have a higher anxiety level, while the boys are more aggressive and have a high expectation for success. The difference between male and female in reference to aggressiveness and expectation for success is a finding that determines those two characteristics. Referring to dependence and anxiety there is no understanding among the researchers. In an unpublished article there was written that concerning dependence and anxiety the girls consistently achieve higher that the boys. However, there are no data stating that the boys are less dependent and less anxious than the girls, it was only stated that the boys consistently are less dependent and less anxious. The relationship between those above personal characteristics and intellectual performance differ between boys and girls. For example, a feeling of shyness, being careful and other components concerning anxiety are positively correlated with IQ of the boys but not with that of the girls.

Most psychologists and sociologists look at the difference of gender from the point of role training and social expectation. Since at the age of 2 or 3 years the boys and girls have had a different attitude and a different interest, which are then influenced and reinforced by the parents.

It seems that the academic performance and motivation of the boys are contradicting to those of the girls in the elementary schools, high schools and college level. In general the boys experience difficulties in the elementary schools. In line with the teachers' reports the boys in the elementary schools are more aggressive, show worse academic performance, have lower level of frustration and boredom, show higher level of activity, and have shorter concentration span than the girls (Dembo, 1991).

At the early stages in high school the boys show a better academic performance than the girls. Being successful in choosing a vocation has become an important component to show his identity as a male being for the boys, and the adolescent boys are more interested to master subject matters that are related to vocational purposes.

\section{RESEARCH METHOD}

This is an ex post facto study as the variables under investigation cannot be manipulated.

The variables under study are as follows:
1. independent variables : cognitive learning styles, namely field-dependent \& field- independent

2. controlled variables : gender: male \& female

3. dependent variable : academic achievement

Population. The population of this study is SMU students of IPS classes(Social Science Classes) and of IPA classes (Mathematic and Natural Science Classes). The reason why those two kinds of classes are chosen is because some subject matters are given in both kinds of classes.

Sample. The sample in this study are SMU students of IPS and IPA classes level 3, "SMUK TRIYANA"

Sampling technique. The sampling technique employed is random. The class it self is an intact group.

Design. The independent variables in this study cannot be manipulated; as such there was no treatment for them. The statistical analysis employed is $2 \times 2$ ANOVA, namely cognitive learning styles (fieldindependent or $\mathrm{FI}><$ field-dependent or $\mathrm{FD}$ ) and gender (male $><$ female).

\section{$2 \times 2$ ANOVA}

CLS

FI/IPA

FD/IPS

GENDER

M

Note : FI $=$ Field-independent/IPA $(\mathrm{m} 1)$ FD $=$ Field-dependent/IPS $(\mathrm{m} 2)$

Instrument. The research instrument is the summative test at the end of the schoolyear.

Scope of the study. This study covers only the achievement of level 3 
SMU students, i.e. those of IPA classes (field-independent) and those of IPS classes (field-dependent) within the scope of two cognitive styles, namely field-independent and field-dependent coveringboth male as well as female students. The subject under study are History, a content subject, and English, a skill subject.

\section{HYPOTHESES}

In reference to the theoretical framework and as a tentative answer to the research problems, some hypotheses are deducted as follows:

1. There is a different effect on the achievement of students who have field-dependent cognitive learning style and those who have fieldindependent cognitive learning style.

2. Field-independent cognitive learning style has greater effect on the academic achievement of students.

3. There is an interaction between cognitive learning style and gender

Statistical Hypotheses

1. $\mathrm{Ha}: \mathrm{m}_{1} \neq \mathrm{m}_{2}$

Ho: $m=m$

1. $\mathrm{Ha}: \mathrm{m}_{1}>\mathrm{m}_{1}$

Ho: $m_{1}=m_{2}$

1. $\mathrm{Ha}$ : Int. CLSX G $\neq 0$

Ho: Int. CLS X G $=0$

Level of Confidence or alpha $=0.05$

Note:

$\mathrm{m}_{1}=$ mean score of achievement of students who are field-independent

$\mathrm{m}_{2}$ = mean score of achievement of students who are field-dependent CLS = cognitive learning style

$\mathrm{G}$ = gender

\section{DEFINTTION OF TERMS}

Field-dependent people work more globally and easily detracted by all kinds of background/surrounding elements. They are attracted to other people, like to work as teachers. Like to work that involve other people, and prefer academic fields such as social sciences that are more "oriented to other people." (Dembo, 1991). Based on this definition this study includes students who are from Social Science classes (IPS) to those who are field-dependent

Field-independent people can overcome the influence of all kinds of (back-ground/surrounding/field) elements that detracted them. These people like to work as astronomers and engineering, that does not always need to work with other people. The academic fields that these persons choose as their preference is mathematics and physical social sciences that emphasizes on objectives and abstraction. Based on this explanation this study includes students from the Mathematics and Natural Science classes (IPA) as field-independent.

Learner autonomy is a matter of explicit on conscious intention: the learner must at least take some of the initiatives that give shape and direction to the learning process, and must share in monitoring progress and evaluating the extent to which learning targets are achieved.

\section{RESULT OF THESTUDY}

The result of the study is discussed below, beginning with the description of the data:

Description of data:

\section{Sulbject matter: English}

From the tabulation of the obtained data it turned out that: the Mean score of the FI (field-independent) students $=7.846$, while the Mean score of the FD (field-dependent) students $=7.192$.

We can see that the FI students have obtained higher mean score than the FI students, though the difference is not much.

The Mean score of the M(ale) FI students $=7.769$

The Mean score of the F(emale) FI students $=7.923$

The Mean score of the M(ale) FD students $=7.077$

The Mean score of the F(emale) FD students $=7.308$

We can see the difference of mean scores among those four groups, however the significance of those differences has still to be statistically tested by employing the $2 \times 2$ ANOVA statistical analysis.

\section{Subject matter: History}

From the tabulation of the obtained data it is shown that:

The Mean score of the FI students $=6.982$

The Mean score of the FD students $=6.615$

As the case is with English, in this subject matter (History) the FI students 
have got higher achievement score than those of FD students, but again the difference is not much.

The Mean score of the M(ale) FI students $=6.846$

The Mean score of the F(emale) FI students $=7.077$

The Mean score of the M(ale) FD students $=6.846$

The Mean score of the $\mathrm{F}$ (emale) FD students $=6.385$

Whether it is by chance or not, the fact is that magnitude of the Mean score of the M(ale) FI as well as FD students is equal (6.846). However, similar to English (subject matter) the equality or the differences found in the obtained data should be statistically tested.

\section{DATA ANALYSIS}

From the analysis of variance $2 \times 2$ it is shown that:

\section{Subject matter: English}

The $\mathrm{F}$ table at df $1 / 48$ and alpha $0.05=4.04$, while

At alpha0.01 $=7.19$

This study had set alpha at 0.05 when constructing the hypotheses.

The obtained $\mathrm{F}$ ratio $=6.515$

The $\mathrm{F}$ table $=4.04$

It means that the obtained $\mathrm{F}$ ratio is significant which leads to the rejection of the first null hypothesis (there is no different effect on the achievement of FI and FD students). Thus, it means that there is a difference of effect on the achievement of FI and FD students. Which achievement is higher? The Mean score of the FI students $=7.846$, while that of the $\mathrm{FD}$ students $=7.192$.

This gives the interpretation that the 2 nd null hypothesis (The fieldindependent cognitive learning style has equal effect as the field-dependent learning style) is also rejected. The conclusion is: The fieldindependent cognitive learning style has greater effect than the fielddependent learning style.

The obtained F ratio for FI as well as FD male and female students = 0.563

The $\mathrm{F}$ table $=4.04$

This shows that the obtained F ratio is not significant which means that the 3rd null hypothesis (There is no interaction between Cognitive
Learning Style and Gender) is retained. In other words it can also be said that gender does not have any influence on students' achievement.

\section{Subject matter: History}

Concerning History, the result of the analysis is a bit different from English. The analysis of the History data revealed that all the three null hypotheses are retained. This means that there is no effect on the achievement of FI as well as FD students. In other words, in History the cognitive learning style has no effect on achievement.

\section{DISCUSSION}

Based on the data analysis for the subject matter English, one of the three hypotheses is rejected, while for the subject matter History all three hypotheses failed to be rejected. Probably, the reasons why the null hypotheses failed to be rejected is because:

1. There was an error in the sampling technique. The school used as sample, "SMUK TRIYANA", is a good school, that is to say the students are very disciplined. Enrollment of the students are very strict and the headmasters as well as the teachers follow the regulation and so do the students. These factors might be the cause that the students are almost homogenous.

2. History is a content subject and English is a skill subject. From the data analysis it was revealed that concerning the subject matter English, the FI students had higher achievement than the FD students. The FI students are students from IPA classes who are used to handle mathematical problems everyday. Most probable there is positive correlation between the achievement and mathematics. As for the subject matter History, which is a content subject, the achievement between the FI and FD students are the same.

3. The sample in each group is mot much, only 13 students. That there was no effect of gender on achievement is in line with the data revealed by Good and Brophy (1995). They said that there was an improvement on the effort of abolishing the notion that there had to be made a difference between male and female in society. Also Feingold (1992) has made a conclusion that the great difference in participation between male and female has disappeared these last years. 


\section{CONCLUSION}

It is revealed in this study that cognitive learning style, namely fieldindependent and field-dependent, does not have any effect on the achievement of students in History (subject matter); on the other hand it has an effect on English (subject matter). As for the variable gender, it has no effect on students' achievement.

The result of this study might be one of the factors to be taken into consideration by teachers if they want to apply learning autonomously in their classes. As they can take measure which students to encourage, how far to encourage, and how to encourage so that learner autonomy can be promoted in the class.

\section{RECOMMENDATION}

In reference to the result of this study, it would be much better to have a replication of this research:

1. using a greater sample size

2. not only focusing on content and skill subject matters

3. a more detailed study on gender, as there are still many relevant researches that reveal a difference in achievement, especially in the discipline of sciences.

\section{REFERENCES}

Ary, D; Jacobs, L.C. and Razavieh, A. 1984. Introduction to Research in Education. New York: Holt Rinehart dan Winston.

Dembo, M.H. 1991. Teaching for Learning: Applying Educational Psychology in the Classroom (2nd ed.). Santa Monica, California: Goodyear Publishing Company, Inc.

Feingold, A. 1992. Sex Differences in Variability in Intellectual Abilities: a New Look at an Old Controversy. Review of Educational Research, 62, (1), 61-84.

Good, T.L. and Brophy, J.E. 1995. Looking in Classrooms (4th ed.). New York: Harper \& Row, Publishers.

Hagen, E.P. and Thordike, R. L. 1994. Measurement and Evaluation in Psychology and Education. Tanpa penerbit.

Henson, K.T. 1994. Instruction and Learning: Then and Now. Theory into Practice. Tanpa penerbit.

Kfir, Drora. 1994. Achievements and Aspirations among Boys and Girls in High School: a Comparison of Two Israeli Ethnic Groups. American Educational Research Journal, 25, (2), 213-236.
Little, D. 1991. Learner Autonomy 1: Definitions, Issues and Problems. Internet. Marsh, H.W. 1992. Sex Differences in the Development of Verbal and Mathematics Contructs: the High School and Beyond Study. American Educational Research Journal, 26, (2), 191-225.

Mc Garry, D. 1995. Learner Autonomy 4: the Role of Authentic Texts. Internet. Stipek, D. J. and Weisz, J. R. 1994. Perceived Personal Control and Academic Achievement. Review of Educational Research, 51, 101-137.

Ware, N.C. and Lee, Valerie E. 1996. Sex Differences in Choice of College Science Majors. American Educational Research Journal, 25, (4), 593-614.

Weiner, B., Rusell, D. and Lerman, D. 1996. The Cognition-emotion Process in Achievement-related Contexts. Journal of Personality and Social Psychol ogy, 77, 608-618. 